\title{
APPLIED EPIDEMIOLOgY TRAINING IN EUROPE: QUITE A SUCCESS - BUT MORE TO BE DONE
}

\author{
G Krause (Krause@rki.de) ${ }^{1}$, P Stefanoff², A Moren ${ }^{3}$ \\ 1. Robert Koch Institute, Berlin, Germany \\ 2. National Institute of Hygiene, Warsaw, Poland \\ 3. EpiConcept, Paris, France
}

This article was published on 29 October 2009.

Citation style for this article: Krause G, Stefanoff P, Moren A. Applied epidemiology training in Europe: quite a success - but more to be done. Euro Surveill. 2009;14(43):pii=19375. Available online: http://www.eurosurveillance.org/ViewArticle.aspx?ArticleId=19375

This article describes the development of training in applied epidemiology in Europe and outlines the current situation in Europe with a view of how the system can be improved to meet future challenges.

Applied epidemiology training is often being referred to as training in field or intervention epidemiology. Field epidemiology has been characterised as "quick and appropriate" meaning that it addresses important public health problems in the community in a timely manner and employs the appropriate resources and epidemiologic methods to probe causality to the degree sufficient to identify the source or aetiology of the problem and to establish immediate and long term control and prevention accordingly [1].

\section{The origin of training in field epidemiology}

The first structured programme deliberately focussing on applied epidemiology training was the Unites States Centers for Disease Control and Prevention (US CDC) Epidemic Intelligence Service (EIS). It was founded in 1951 by Alexander Langmuir as a two-year on-the-job training at the CDC. [2]. Although the scope of topics to be covered and some of the methods have further developed since, the hallmark of the EIS remains the combination of a three-week introductory course followed by a two-year public health assignment interrupted only by a few specialised training modules. Due to increasing demand from foreign applicants and also in order to stimulate a common international methodological and conceptual training approach, the CDC started supporting the creation of "Field Epidemiology Training Programmes" (FETP) in many other countries [3-5]. In that context CDC seconded staff as long term consultants, temporary supervisors or course facilitators to other countries and provided training material. The Training Programmes in Epidemiology and Public Health Interventions NETwork (TEPHINET) was founded in 1997 and aims to improve networking between the FETP [6]. Today some 42 FETP are officially members of TEPHINET. Others exist independently from TEPHINET.

\section{The development of field epidemiology training in Europe}

The European Programme for Intervention Epidemiology Training (EPIET) was founded in 1995. It is a special form of FETP as it was set up from the very beginning to have a collaborative, multinational approach [7]. It has been a principle of EPIET that participants coming from one country of the European Union (EU) be assigned to a training site of another EU country, so as to increase networking on the European level.

National FETP also exist in the EU. They generally assign national participants exclusively to training sites within the country, and training is done in the national language. A variation of this are the EPIET-associated programmes in which fellows are assigned to a training site inside their country of origin but attend the modules and receive supervision organised by EPIET. In the following discussion, the FETP, the EPIET and the EPIETassociated programmes will be referred to collectively as the Applied Epidemiology Training Programmes (AETP).

The AETP in Europe generally have similar training objectives. They aim at enabling participants to apply epidemiological tools in the practical public health context. Outbreak investigations, surveillance activities and epidemiologic research represent the core approaches to rapid infectious disease control and are the main focus of the projects to be completed during the programme. European AETP have a lot in common with the EIS as most of the architects of EPIET and heads of the departments hosting the French, the Italian and the German FETP, as well as various facilitators and supervisors, are EIS alumni.

\section{Country-specific aspects of AETP in the EU}

The existing European FETP have different approaches [7]. The Italian programme has a very strong focus on non-communicable diseases and highlights the programmatic and preventive aspects of public health instead of the surveillance and intervention aspects in infectious diseases which largely characterise the other national FETP.

The European FETP also have different strategies for capacity building. The Italian FETP places emphasis on "in house capacity building" where public health workers who already have permanent positions in peripheral health departments are recruited to strengthen their skills in their established functions. The German FETP on the other hand attempts to "attract and specialise external workforce" placing elevated application requirements with respect to prior academic degrees, work experience and language skills in order to attract young scientists from various academic disciplines into the public health workforce. The French and Norwegian programmes are somewhere in between those approaches and the 
Spanish FETP is currently moving from the "in-house capacity building" strategy towards "attracting external workforce".

The Italian, French and Spanish programmes are purely national in that all modules and training activities are carried out within the country without direct interaction with the EPIET or the other FETP. The advantages of offering modules and courses in the national language are that applicants selected for training do not have to be proficient in English. This in turn may attract applicants who are more likely to remain working in the national public health workforce instead of moving on to (possibly more attractive) positions in other countries. On the other hand, for the time being, English remains the lingua franca in medical science: a literature review, foundation of any epidemiological study, requires reasonable English reading skills at least; and sharing epidemiologic findings within the scientific community will in many instances be most effective if done in international scientific networks, journals and conferences. Given the new International Health Regulations and multiple networks within the EU, the ability to communicate in English has become a daily necessity on national level. This will inevitably and increasingly hold true also for local public health officers. One very important and successful characteristic of EPIET is to require proficiency in English and at least one other European language. During the EPIET fellows have to learn the language of their hosting country. This sometimes represents a tremendous challenge. However this challenge has many benefits. Being exposed to other languages and cultures, EPIET fellows become better equipped to negotiating and networking at the European level. Because of these very reasons it would therefore be desirable that English language proficiency also be required and developed in national FETP, so that fellows and alumni of national FETP can also be active members of the European epidemiologists network as EPIET and EPIET-associated programmes' fellows already are.

\section{Academic recognition and accreditation}

Applied epidemiology training differs from university-based training such as the Master in Public Health (MPH) or Master of Science in Epidemiology programmes. Master studies are usually characterised by a typical "class room" kind of curriculum. Applied epidemiology training is typically organised as a two-year full time programme in which over $80 \%$ of the time is filled with supervised on-the-job training. Lectures, seminars, case studies and other training formats common in academic training only make up for less than $20 \%$ of the time [8].

The Spanish FETP (PEAC) has a strong "class room" approach requiring fellows to attend a three-month introductory course at the national local school of public health (Escuela Nacional de Sanidad, ENS). The French, German and Italian FETP also cooperate with universities to varying degrees but without it affecting the on-thejob training approach.

Graduates of the Italian and Spanish FETP receive a MPH. Similarly the German FETP is now providing a Master of Science in Applied Epidemiology upon completion. Those formal titles have immediate implications on career chances and salaries in many European countries. Other AETP such as EPIET or the French FETP do not result in academic diplomas. The fellows that attend those programmes can however individually use the teaching modules and practical work conducted during their training to gain academic credits with specific European universities. Many alumni believe that, given the quality of the AETP, it should be appropriate that successful completion of the two-year programmes be acknowledged accordingly. Others recognise that pursuing an $\mathrm{MPH}$ and an AETP at the same time could jeopardise the quality of both.

It should be noted that the EIS, in over 50 years of its existence in the United States (US), never needed to be recognised with an academic degree. The visibility of the EIS programme and the career boost that it represents relies mainly on the quality of the work performed during the two-year training. Most EIS alumni complement their practical training with an MPH or a PhD degree obtained before or after the EIS programme.

In Europe academic diplomas do not automatically imply professional accreditation or board certification in public health medicine or epidemiology. Such accreditation is lacking in many countries and at the European level. However it must be recognised that the combination of an $\mathrm{MPH}$ and an AETP with an EU professional accreditation would provide a good basis for a career in field epidemiology. Applied epidemiology training is therefore not redundant to public health or preventive medicine training but should rather be seen as complementary.

\section{Role of AETP in epidemiology training capacity in the EU}

FETP and EPIET have been commended for the high level of training quality and the successful integration of alumni in the European public health workforce [9]. In the last 15 years EPIET and FETP fellows have participated in most of the major outbreak investigations conducted at the national and EU level as well as in the response to major international outbreaks [10]. They constitute a force of intervention within Europe and to some extend beyond it although the involvement of the European Centre for Disease Prevention and Control (ECDC) in activities outside EU is limited.

While EIS officers and most FETP fellows are regular staff members of the respective institutions, EPIET fellows are currently funded through a scholarship, in order to overcome specific administrative obstacles within the EU regulations. This scholarship status however runs the risk that EPIET participants are seen and see themselves as students, without the privileges and duties of regular staff members. EPIET and especially the respective training sites must therefore take care that EPIET fellows be visible as full members of the European workforce in intervention epidemiology.

While the expansion of EPIET in the recent years is impressive, the needs in terms of human resources are not met. The European training capacity lags behind the US EIS as far as the number of trained experts is concerned [11]. In the US with a population of around 305 million people the EIS has currently around 80 EIS officers per cohort, that is to say it is training about one expert per 3.8 million inhabitants [12]. In comparison, in the EU and EFTA countries with a population of about 505 million people, EPIET and all FETP taken together have around 50 fellows per cohort which would result in one expert per 10.1 million inhabitants. Furthermore this very rough comparison does not take into account three additional factors: first, the need for field epidemiologists is not only determined by the size of the population but also by the number and complexity of administrative levels; second, the long existence of EIS has already generated a solid basis of a field epidemiologist workforce; and third, a number of states in the US have their own complementary field epidemiology training programmes which have not been included in the calculation above. 
For all these reasons it seems save to say that the European training capacity for applied epidemiology should be increased.

AETP are very resource-intensive. They usually operate on the borderline of the mandates of ministry of health and ministry of research and education and generate conflicts regarding their funding by national, regional or local governments. This mixture leads to a situation in which the need of such programmes is easily agreed upon yet the organisational and financial responsibilities are often being disputed between various entities. Most of the five existing FETP in Europe have undergone critical phases when the source of funding was uncertain and other administrative problems impeded their functioning. For many years Poland and Hungary have tried to initiate FETP. Yet the lack of logistic capacities, especially in terms of human resources, made it impossible so far.

\section{Role of AETP in European integration}

Most countries that accessed the EU after 2004 have large, centralised public health systems, which have undergone several reforms, and different models of public health training have been in place. The main obstacle in capacity building in the new Member States - although not necessarily limited to these countries - is the poor availability of experienced epidemiologists, mostly due to still limited university training. Especially the local public health departments lack professionals who can apply epidemiological methods, perform epidemiological studies, publish their results, and generally use a "language" common with their Western colleagues.

Well-trained epidemiologists from the new Member States often choose a carrier in Western Europe, the US or in international organisations, due to much higher salaries and an environment more suitable to their professional development. This situation creates barriers for the development of FETP programmes in these countries since the few epidemiologists working there are not available as supervisors. The role of EPIET in this matter is also limited as only few EPIET alumni from the "new" EU countries have returned to their home countries to help in capacity building.

Future perspectives of applied epidemiology training in Europe

The capacity building in applied epidemiology in Europe is likely to be more successful if new FETP and EPIET-associated programmes are created and integrated in a European Network of national FETP rather than increasing the size of EPIET alone. According to Article 9 of the founding regulation of ECDC it is one of its tasks to "assist Member States to have sufficient numbers of trained specialists, in particular in epidemiological surveillance and field investigations, and to have a capability to define health measures to control disease outbreaks" [13]. Therefore it seems it should be a priority for ECDC not only to run EPIET and offer training courses (which it is already doing) but also to assist Member States in creating FETP and to support the concept of EPIET-associated programmes.

It should be acknowledged that the Spanish, German and Italian FETP benefitted from the secondment of US CDC experts to those countries [3]. Following this example, seconding EU senior epidemiologists to European countries willing to develop an FETP is a practice that needs to be further developed and accepted by Member States. With ECDC hosting a stable and ever increasing EPIET, the conditions have never been as good and the steps to be taken never as clear to actually foster cooperation between existing FETP and to create new ones in Europe.

National ministries of health need to assume responsibility in generating and assuring an internationally compatible workforce in applied epidemiology, including the creation of national applied epidemiology training programmes while EPIET should function as a breeding ground for these programmes.

\section{Acknowledgements}

In July 2008 current and former coordinators of EPIET and the five existing FETP as well as representatives of two national public health institutes planning to initiate an FETP met in Berlin to discuss the future of field epidemiology training programmes and their interaction with EPIET. We would like to thank the participants of this workshop for contributing their perspectives and thoughts which laid the foundation to this manuscript: P. Aavitsland, K. Alpers, A. Barrasa, N. Binkin, A. Bosman, V. Bremer, I. Czumbel, B. Helynck and D. Herrera.

\section{References}

1. Goodman RA, Buehler JW. Field epidemiology defined. In: Gregg MB, editor. Field Epidemiology. New York: Oxford University Press; 2002. p. 3-7.

2. Thacker SB, Dannenberg AL, Hamilton DH. Epidemic intelligence service of the Centers for Disease Control and Prevention: 50 years of training and service in applied epidemiology. Am J Epidemiol. 2001;154(11):985-92.

3. Ammon A, Hamouda O, Breuer T, Petersen LR. The Field Epidemiology Training Program (FETP) in Germany. Euro Surveill 2001;6(3):43-5. Available from: http:// www.eurosurveillance.org/ViewArticle.aspx?ArticleId $=219$

4. Lopez A, Caceres VM. Central America Field Epidemiology Training Program (CA FETP): a pathway to sustainable public health capacity development. Hum Resour Health. 2008;6:27.

5. White ME, McDonnell SM, Werker DH, Cardenas VM, Thacker SB. Partnerships in international applied epidemiology training and service, 1975-2001. Am J Epidemiol. 2001;154(11):993-9.

6. Cardenas VM, Roces MC, Wattanasri S, Martinez-Navarro F, Tshimanga M, AlHamdan N, et al. Improving global public health leadership through training in epidemiology and public health: the experience of TEPHINET. Training Programs in Epidemiology and Public Health Interventions Network. Am J Public Health. 2002;92(2):196-7.

7. van Loock F, Rowland M, Grein T, Moren A. Intervention epidemiology training: a European perspective. Euro Surveill 2001 March;6(3):37-43. Available from: http://www.eurosurveillance.org/ViewArticle.aspx?ArticleId=218

8. Krause G, Aavitsland P, Alpers K, Barrasa A, Bremer V, Helynck B, et al. Differences and Commonalities of National Field Epidemiology Training Programmes in Europe. Euro Surveill. 2009;14(43):pii=19378. Available from: http://www.eurosurveillance.org/ViewArticle.aspx?ArticleId =19378

9. Bremer V, Bosman A, Coulombier D. New perspectives after the transition of EPIET to ECDC - the future of the programme. Euro Surveill. 2009;14(43):pii=19374. Available from: http://www.eurosurveillance.org/ ViewArticle.aspx?ArticleId $=19374$

10. Bosman A, Schimmer B, Coulombier D. Contribution of EPIET to public health workforce in the EU, 1995-2008. Euro Surveill. 2009;14(43):pii=19381. Available from: http://www.eurosurveillance.org/ViewArticle.aspx?ArticleId=19381

11. Ostroff SM. The Epidemic Intelligence Service in the United States. Euro Surveill. 2001;6(3):34-6. Available from: http://www.eurosurveillance.org/ ViewArticle. aspx?ArticleId $=216$

12. Walke HT, Simone PM. Building capacity in field epidemiology: lessons learned from the experience in Europe. Euro Surveill. 2009;14(43):pij=19376. Available from: http://www.eurosurveillance.org/ViewArticle.aspx?ArticleId=19376

13. Regulation (EC) No 851/2004 of the European Parliament and of the Council of 21 April 2004, 851/2004 establishing a European centre for disease prevention and control (ECDC), Official Journal l 142, 30/04/2002 P. 1-11. Available from: http:// eur-lex.europa.eu/LexUriServ/LexUriServ.do?uri=CELEX:32004R0851:EN:HTML 